\title{
Effects of Aripiprazole and Haloperidol on Fos-like Immunoreactivity in the Prefrontal Cortex and Amygdala
}

\author{
Jong-II Park', Tong Zhao², Guang-Biao Huang ${ }^{2}$, Zhi-Yan Sui ${ }^{2}$, Chun-Rong Li ${ }^{2}$, Eui-Hyeog Han $^{3}$, Young-Chul \\ Chung ${ }^{1,2}$
}

Department of Psychiatry, ${ }^{1}$ Chonbuk National University Hospital \& Research Institute of Clinical Medicine, ${ }^{2}$ Chonbuk National University Medical School \& Institute for Medical Sciences, ${ }^{3}$ Department of Anatomy, Chonbuk National University Medical School \& Institute for Medical Sciences, Jeonju, Korea

\begin{abstract}
Objective: Aripiprazole, a dopamine system stabilizer, shows efficacy against both negative symptoms and positive symptoms in patients with schizophrenia. The aim of this study was to investigate the effects of aripiprazole and haloperidol on c-FOS expression in rat brain.

Methods: Aripiprazole (1, 10 and $30 \mathrm{mg} / \mathrm{kg}$, i.p.) and haloperidol $(0.1$ and $1 \mathrm{mg} / \mathrm{kg}$, i.p.) were administered to adult Male Sprague-Dawley rats. After $2 \mathrm{~h}$ of drug or vehicle administration, the rats were killed and their brains were removed and perfused with fixative, then cut into $40 \mu \mathrm{m}$ slices on a freezing microtome. Brain regions of interest were the medial prefrontal cortex (mPFC), the nucleus accumbens core and shell (NAC-C and NAC-S), the hippocampus (CA1, CA3 and DG), the central amygdala $(\mathrm{Ce})$, the basolateral amygdala $(\mathrm{BL})$ and the temporal cortex $(\mathrm{TC})$. Immunohistochemistry was performed to label cell bodies containing C-FOS.

Results: The administration of aripiprazole at all doses (1, 10 or $30 \mathrm{mg} / \mathrm{kg}$ ) resulted in greater Fos-like immunoreactivity (FLI) in the investigated brain areas, as compared to the vehicle. Comparable increases in FLI were demonstrated in the NAC-C and NAC-S in response to both aripiprazole and haloperidol treatment. The administration of haloperidol $(0.1 \mathrm{or} 1 \mathrm{mg} / \mathrm{kg}) \mathrm{also}$ resulted in greater FLI in the investigated brain areas, except the MPFC, where no changes were observed. In the Ce and $\mathrm{BL}$, a significant increase in Fos-positive neurons was observed only with $0.1 \mathrm{mg} / \mathrm{kg}$ of haloperidol,

Conclusion: Both aripiprazole and haloperidol increased FLI in limbic areas, which are considered important targets of antipsychotic drugs. The differential action of aripiprazole on FLI in the amygdala and mPFC as compared to haloperidol may be a good way to differentiate atypical from typical antipsychotics.
\end{abstract}

KEY WORDS: Aripiprazole; c-FOS; Haloperidol.

\section{INTRODUCTION}

The proto-oncogene c-fos has received special attention within the neurophysiological community as it may serve as a useful marker of brain regions activated following various physiological stimuli. Because the expression of Fos, the protein product of c-fos, is correlated with neuronal activation, Fos immunohistochemistry (IHC) has become a useful tool to map the functional pathways of the central nervous system. In particular, pharmacological studies suggest that Fos IHC can be used to identify the

\footnotetext{
Received: December 15, 2010 / Revised: April 1, 2011

Accepted: April 5, 2011

Address for correspondence: Young-Chul Chung, MD

Department of Psychiatry, Chonbuk National University Medical

School, 634-18 Keumam-dong, Deokjin-gu, Jeonju 561-712, Korea

Tel: +82-63-250-2185, Fax: +82-63-275-3157

E-mail: chungyc@chonbuk.ac.kr
}

potential neuroanatomical sites of drug action. Using this methodology, it has been shown that typical and atypical antipsychotics induce the same pattern of Fos-like immunoreactivity (FLI) in the nucleus accumbens (NAC) and lateral septum. In contrast, differential patterns of FLI arise in the striatum and prefrontal cortex (PFC) in response to antipsychotics that are predictive of whether a drug causes extrapyramidal side effects and is effective in treating the negative symptoms of schizophrenia. Robertson et al. ${ }^{1)}$ claimed that typical and atypical antipsychotics could be distinguished on the basis of an index obtained by subtracting the extent of FLI induction in the dorso-lateral striatum from FLI in the NAC. If the index is negative, the drug is a typical antipsychotic, and if positive, an atypical antipsychotic. Nevertheless, in most previous studies the neuroleptics examined were limited to haloperidol or clozapine and the brain regions examined were mainly stria- 
tum or NAC. We have a special interest in the amygdala (Amyg), temporal cortex (Tc), and hippocampus (HIP) regions and therefore included these regions in the present study. The Amyg plays a central role in neuronal signaling of fear memory, which is closely implicated in the pathogenesis of schizophrenic symptoms. The Tc has recently been proposed as a common site of action for antipsychotics based on the finding that clozapine resembles other antipsychotics in its ability to cause high levels of $\mathrm{D}_{2}$ receptor occupancy in the temporal cortex. ${ }^{2,3)}$ The HIP abnormalities have been reported in the postmortem studies in schizophrenia. ${ }^{4)}$ Chung et al. $^{5)}$ suggested that clozapine's superior action on cognition compared to haloperidol may be related to its greater action on the release of dopamine in the HIP.

Aripiprazole is a recently introduced, second-generation antipsychotic that has a receptor-binding profile that is distinct from those of other second-generation antipsychotics. This drug is a partial agonist at $\mathrm{D}_{2}$ and 5-hydroxytryptamine $(5-\mathrm{HT})_{1 \mathrm{~A}}$ receptors and is also an antagonist at $5-\mathrm{HT}_{2 \mathrm{~A}}$ receptors. Only a few studies have been conducted with regard to the effects of aripiprazole on c-FOS expression: FOS expression for aripiprazole in the accumbens shell became observable only at occupancies exceeding $80 \% \mathrm{D}_{2}$ receptor occupancy ${ }^{6)}$ and an increase in expression of the c-fos mRNA in the striatum was not demonstrated by aripiprazole. ${ }^{7}$ However, action of aripiprazole in the Amyg, Tc and HIP has never been investigated using Fos IHC. The objectives of the present study were to evaluate the induction of c-Fos by measuring FLI in areas of the rat brain, including the Amyg, Tc and HIP after acute administration of aripiprazole and haloperidol.

\section{METHODS}

\section{Animals}

Adult male Sprague-Dawley rats (Orient Bio Inc, Korea), weighing 200-250 g, were used. They were housed in groups of 3-4 in a temperature-controlled room under light/dark cycle (lights on from 7:00-19:00) with food and water ad lib. All possible efforts were made to minimize animal suffering and the number of animals used, in accordance with the Guidelines for Animal Experiments of Chonbuk National University Medical School.

\section{Drugs}

Haloperidol was purchased from Sigma (USA) and ari- piprazole was generously provided by the Otsuka Pharmaceutical Company (Japan). Haloperidol and aripiprazole were dissolved in $0.1 \mathrm{M}$ tartaric acid and $45 \%$ 2-hydroxypropyl- $\beta$-cyclodextrin (HBC) (Sigma, USA), respectively. All solutions were adjusted to a final $\mathrm{pH}$ of 5-6 with $\mathrm{NaOH}$. Thus, the study was comprised of the following four groups: aripiprazole, haloperidol and two controls (45\% HBC and 0.1 M TTA). Drug groups received one of the following five treatments: aripiprazole $(1,10$ or $30 \mathrm{mg} / \mathrm{kg}$ ) or haloperidol $(0.1$ or $1 \mathrm{mg} / \mathrm{kg})$. All solutions were freshly prepared and administered intraperitoneally at a volume of $1 \mathrm{ml} / \mathrm{kg}$. The doses were chosen on the basis of therapeutic equivalency for haloperidol and previous reports for aripiprazole. ${ }^{6,8)}$ To minimize the influence of stress on the induction of FLI, rats were habituated to the manipulation that preceded the injection for 4 days before the experiment. Rats were also kept in a familiar cage in the animal room during the experiment. Two hours after injection, all of the animals were deeply anesthetized with a ketamine/xylazine mixture (4:1) and were perfused first with $200 \mathrm{ml}$ of calcium-free Tyrode's solution and then with $200 \mathrm{ml}$ ice-cold $4 \%$ paraformaldehyde in $0.1 \mathrm{M}$ TPBS through the left cardiac ventricle to remove circulating blood. Each brain was removed immediately after perfusion, placed in fresh fixative for at least $4 \mathrm{~h}$ and then transferred to sucrose solutions (20\% for 12 $\mathrm{h}$ followed by $30 \%$ for $24 \mathrm{~h}$ ) in $0.1 \mathrm{M}$ TPBS. The brains were embedded with OCT in liquid nitrogen and kept at $-80^{\circ} \mathrm{C}$ until further use.

\section{Immunohistochemistry}

Coronal, $40-\mu \mathrm{m}$-thick sections were cut using a cryostat microtome. Regions of interest in the brain were the prefrontal cortex (PFC), nucleus accumbens core and shell (NAC-C and NAC-S), hippocampus (CA1, CA3 and $\mathrm{DG})$, central amygdala (Ce), basolateral amygdala (BL), and temporal cortex (TC). Cryoprotected, fixed sections were washed three times in TPBS and then bathed for 10 min in $0.3 \% \mathrm{H} 2 \mathrm{O} 2$ to block endogenous peroxidase. Sections were blocked in 3\% normal goat serum and $0.3 \%$ triton X-100 in TPBS for $1 \mathrm{~h}$, and then washed and incubated overnight at $4{ }^{\circ} \mathrm{C}$ with polyclonal rabbit anti-c-fos antibody (1:10,000) (Calbiochem, USA). The sections were washed three times with TPBS and then incubated for $1 \mathrm{~h}$. with rat adsorbed biotinylated anti-rabbit IgG (Vector, USA) diluted $1: 200$ in a solution containing 3\% normal goat serum and $0.3 \%$ triton $\mathrm{X}-100$ in TPBS. Finally, the sections were washed, incubated with $\mathrm{ABC}$ reagents (Vector, USA) for $1 \mathrm{~h}$, and FLI visualized using 
Table 1. Number of Fos-like positive neurons after acute administration of aripiprazole in rat brain

\begin{tabular}{|c|c|c|c|c|c|c|c|c|c|c|c|}
\hline \multirow{2}{*}{$\begin{array}{l}\text { Brain } \\
\text { regions }\end{array}$} & \multirow{2}{*}{$\begin{array}{l}\text { Vehicle } \\
\qquad(n=8)\end{array}$} & \multirow{2}{*}{$\begin{array}{c}\text { ARI } 1.0 \\
\mathrm{mg} / \mathrm{kg} \\
(\mathrm{n}=8)\end{array}$} & \multirow{2}{*}{$\begin{array}{c}\text { ARI } 10.0 \\
\mathrm{mg} / \mathrm{kg} \\
(\mathrm{n}=8)\end{array}$} & \multirow{2}{*}{$\begin{array}{c}\text { ARI } 30.0 \\
\mathrm{mg} / \mathrm{kg} \\
(\mathrm{n}=8)\end{array}$} & \multirow[b]{2}{*}{ p-value } & \multicolumn{6}{|c|}{ ANOVA followed by Sheffe test } \\
\hline & & & & & & $\begin{array}{c}\text { Vehicle vs. } \\
\text { ARI } 1.0\end{array}$ & $\begin{array}{c}\text { Vehicle vs. } \\
\text { ARI } 10.0\end{array}$ & $\begin{array}{c}\text { Vehicle vs. } \\
\text { ARI } 30.0\end{array}$ & $\begin{array}{c}\text { ARI } 1.0 \text { vs. } \\
\text { ARI } 10.0\end{array}$ & $\begin{array}{c}\text { ARI } 1.0 \text { vs. } \\
\text { ARI } 30.0\end{array}$ & $\begin{array}{c}\text { ARI } 10.0 \text { vs. } \\
\text { ARI } 30.0\end{array}$ \\
\hline mPFC & $33.23 \pm 3.23$ & $50.44 \pm 6.77$ & $64.41 \pm 3.69$ & $58.78 \pm 8.02$ & 0.004 & NS & $*$ & $*$ & NS & NS & NS \\
\hline NAC-C & $6.95 \pm 1.76$ & $25.81 \pm 5.80$ & $40.56 \pm 6.32$ & $43.62 \pm 7.82$ & $<0.001$ & NS & $\dagger$ & $\dagger$ & NS & NS & NS \\
\hline NAC-S & $8.27 \pm 1.15$ & $22.38 \pm 5.27$ & $38.48 \pm 4.99$ & $46.12 \pm 7.31$ & $<0.001$ & NS & $*$ & $\dagger$ & NS & $*$ & NS \\
\hline CA 1 & $10.16 \pm 0.97$ & $23.61 \pm 4.28$ & $18.14 \pm 1.55$ & $34.22 \pm 7.10$ & 0.004 & NS & NS & $*$ & NS & NS & NS \\
\hline CA3 & $7.56 \pm 1.59$ & $11.62 \pm 1.21$ & $19.17 \pm 1.62$ & $37.78 \pm 7.93$ & $<0.001$ & NS & NS & $\dagger$ & NS & $*$ & $*$ \\
\hline DG & $18.98 \pm 2.54$ & $33.49 \pm 4.15$ & $38.33 \pm 3.45$ & $52.80 \pm 5.87$ & $<0.001$ & $*$ & $*$ & $\dagger$ & NS & $*$ & NS \\
\hline $\mathrm{Ce}$ & $15.44 \pm 1.81$ & $19.89 \pm 1.98$ & $30.72 \pm 2.93$ & $42.84 \pm 7.56$ & $<0.001$ & NS & $*$ & $*$ & NS & $*$ & NS \\
\hline $\mathrm{BL}$ & $11.09 \pm 1.47$ & $19.38 \pm 1.41$ & $21.01 \pm 1.60$ & $25.56 \pm 2.04$ & $<0.001$ & $*$ & $*$ & $\dagger$ & NS & NS & NS \\
\hline Tc & $24.42 \pm 3.16$ & $38.09 \pm 6.83$ & $32.25 \pm 2.00$ & $89.40 \pm 7.33$ & $<0.001$ & NS & NS & $\dagger$ & NS & $\dagger$ & $\dagger$ \\
\hline
\end{tabular}

Vehicle, 45\% 2-hydroxypropyl- $\beta$-cyclodextrin; ARI, aripiprazole; mPFC, medial prefrontal cortex; NAC-C, nucleus accumbens core; NAC-S, nucleus accumbens shell; DG, dentate gyrus; Ce, central amygdala; BL, basolateral amygdala; Tc, temporal cortex; NS, non-significant. ${ }^{*} p<0.05 ;{ }^{+} p<0.001$.

3,3-diaminobenzidine (Sigma, USA) and $0.2 \%$ nickel chloride intensification. The sections were mounted on gelatin-subbed slides and the slides were dried, dehydrated in ethanol (70-100\% gradually), cleared in xylene, and coverslipped.

\section{Quantification}

FLI was analyzed using MetaMorph ${ }^{\circledR}$ image analysis software (Universal Imaging, West Chester, PA, USA) by a single, treatment-blind observer. Sections were viewed at $100 \times$ magnification and FLI staining was assessed within rectangular grids of defined size: $300 \times 500 \mu \mathrm{m}^{2}$ (NAC-C and NAC-S), $400 \times 400 \mu \mathrm{m}^{2}$ (Ce and BL), 500× $500 \mu \mathrm{m}^{2}$ (mPFC and Tc), $0.2 \mathrm{~mm}^{2}$ (CA1 and CA3), 0.6 $\mathrm{mm}^{2}$ (DG). A grid of the predetermined size was placed in each brain region at a fixed position according to the locations of anatomical landmarks. The software calculated average gray-scale levels of background staining for each section. Then, FLI-positive nuclei were automatically counted within the grid if their pixels were $>30$ gray-scale levels darker than the average gray-scale level of each section. This threshold difference was kept constant for all of the digitally captured images. Manual correction was made to the automated counting for each section as necessary. Only darkly labeled, oval-shaped nuclei that matched the above criteria were counted. Counts obtained from the left and right hemispheres in three adjacent sections through an area of interest were averaged to generate one measurement of Fos-positive nuclei per region. Alternate sections, incubated in the absence of primary antibody as an immunohistochemical control, showed no immunostaining.

\section{Data Analysis}

Data are presented as mean \pm SEM for each treatment group. For statistical analysis, a one-way analysis of variance (ANOVA) was performed on the number of FLI-positive nuclei within a specified brain region to compare the aripiprazole and haloperidol treatment groups. Post-hoc individual comparisons were made using Scheffe's test. Differences were considered statistically significant at the $p<5 \%$ level.

\section{RESULTS}

\section{Effects of Acute Aripiprazole Administration on Fos Immunoreactivity}

The mean number of Fos-positive neurons in each brain region after acute aripiprazole treatment is shown in Table 1. Representative photomicrographs of FLI in select brain regions are shown in Fig. 1. Rats treated with aripiprazole at all doses showed significantly more Fos-expressing neurons in all brain regions examined compared to the vehicle-treated controls. In the NAC-S, CA3, DG, Ce, and $\mathrm{Tc}$, dose-dependent increases in the number of Fos-positive neurons were observed. In the $\mathrm{DG}$ and $\mathrm{BL}$, significant FLI was observed even at a small dose, $1 \mathrm{mg} / \mathrm{kg}$ of aripiprazole. However, in the CA1, CA3, and Tc, only 30 $\mathrm{mg} / \mathrm{kg}$ of aripiprazole produced significant increases of FLI.

\section{Effects of Acute Haloperidol Administration on Fos Immunoreactivity}

The effects of acute haloperidol treatment on FLI are shown in Table 2 and Fig. 2. The patterns of FLI induced by acute haloperidol and aripiprazole administration were distinctly different. Acute administration of haloperidol at 


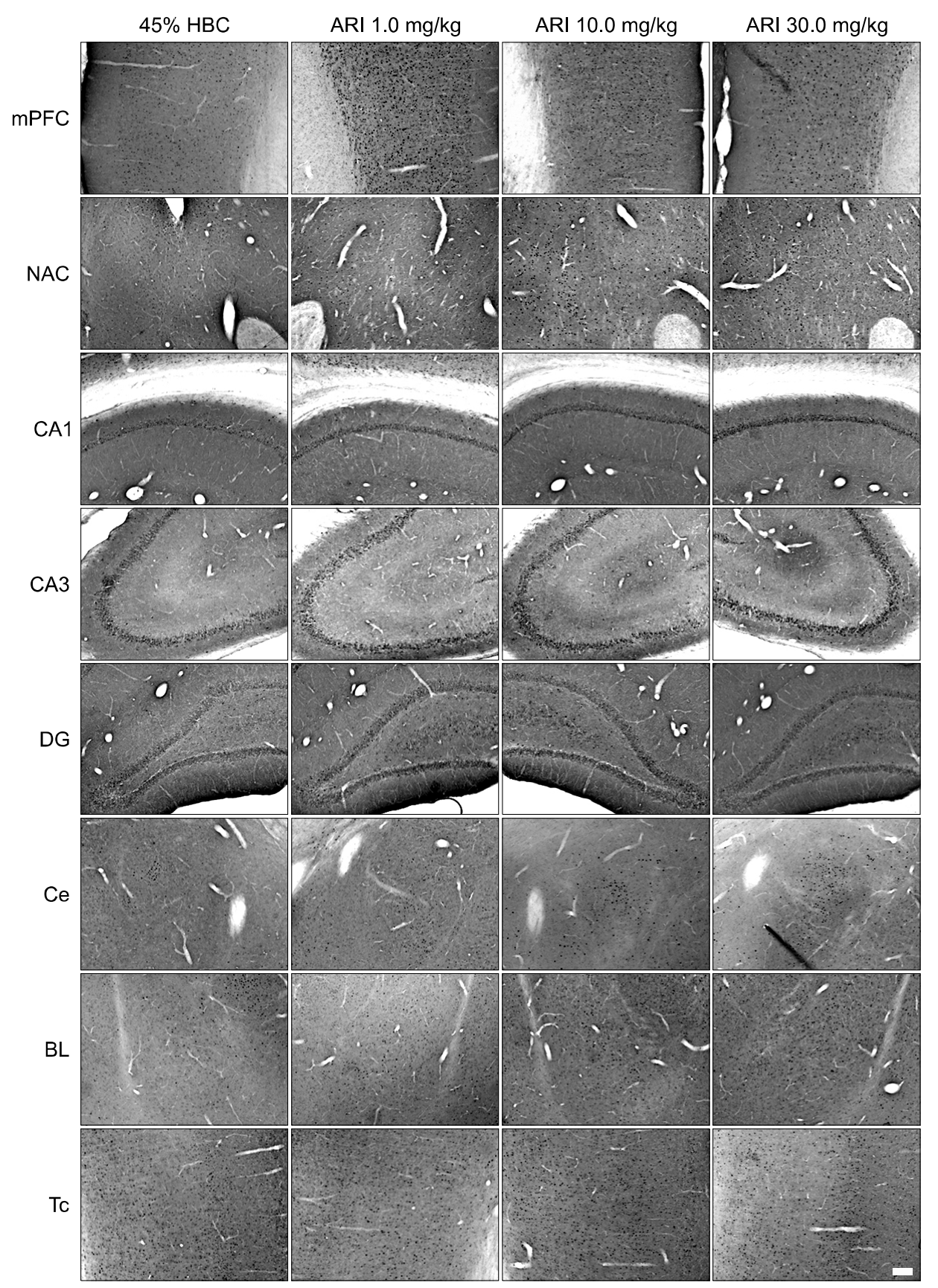

Fig. 1. Representative photomicrographs illustrating the number of Fos-positive neurons in the rat brain after single exposure to antipsychotic agents. HBC, 2-hydroxypropyl- $\beta$-cyclodextrin; ARI, aripiprazole-treated; mPFC, medial prefrontal cortex; NAC, nucleus accumbens; DG, dentate gyrus; Ce, central amygdala; $\mathrm{BL}$, basolateral amygdala; Tc, temporal cortex. $\mathrm{N}=8$ rats/group. Scale bar: $100 \mathrm{um}$.
0.1 or $1 \mathrm{mg} / \mathrm{kg}$ induced a significant increase in Fos-positive neurons compared with vehicle-treated controls in most brain areas examined except the $\mathrm{MPFC}$, where no changes were observed with administration of either 0.1 or $1 \mathrm{mg} / \mathrm{kg}$ of haloperidol. The number of Fos-positive neurons was higher after administration of $1.0 \mathrm{mg} / \mathrm{kg}$ than after $0.1 \mathrm{mg} / \mathrm{kg}$ of haloperidol in the NAC-S, CA3, DG, and $\mathrm{Tc}$. In the $\mathrm{Ce}$ and $\mathrm{BL}$, a significant increase in Fos-positive neurons over vehicle-treated controls was observed only after administration of $0.1 \mathrm{mg} / \mathrm{kg}$ of haloperidol.

\section{DISCUSSION}

Using an IHC technique, the results of the present study show that acute administration of aripiprazole and haloperidol both increased expression of c-Fos in a wide range of brain areas including the Amyg and Tc.

Both aripiprazole and haloperidol treatments caused similar increases in FLI in the NAC-C and the NAC-S. 
Table 2. Number of Fos-like positive neurons after acute administration of haloperidol in rat brain

\begin{tabular}{|c|c|c|c|c|c|c|c|}
\hline \multirow[b]{2}{*}{ Brain regions } & \multirow[b]{2}{*}{ Vehicle $(n=8)$} & \multirow{2}{*}{$\begin{array}{c}\mathrm{HAL} 0.1 \mathrm{mg} / \mathrm{kg} \\
(\mathrm{n}=8)\end{array}$} & \multirow{2}{*}{$\begin{array}{c}\mathrm{HAL} 1.0 \mathrm{mg} / \mathrm{kg} \\
(\mathrm{n}=8)\end{array}$} & \multirow[b]{2}{*}{ p-value } & \multicolumn{3}{|c|}{ ANOVA followed by Sheffe test } \\
\hline & & & & & $\begin{array}{c}\text { Vehicle vs. } \\
\text { HAL } 0.1\end{array}$ & $\begin{array}{l}\text { Vehicle vs. } \\
\text { HAL } 1.0\end{array}$ & $\begin{array}{c}\text { HAL } 0.1 \text { vs. } \\
\text { HAL } 1.0\end{array}$ \\
\hline mPFC & $34.97 \pm 5.00$ & $46.76 \pm 1.95$ & $38.53 \pm 2.89$ & 0.074 & NS & NS & NS \\
\hline NAC-C & $6.68 \pm 0.73$ & $24.66 \pm 1.83$ & $28.15 \pm 1.86$ & 0 & $\dagger$ & $\dagger$ & NS \\
\hline NAC-S & $10.08 \pm 1.59$ & $29.83 \pm 2.72$ & $46.75 \pm 4.36$ & 0 & $\dagger$ & $\dagger$ & $*$ \\
\hline CAl & $18.52 \pm 1.14$ & $39.44 \pm 5.28$ & $44.88 \pm 7.40$ & 0.005 & $*$ & $*$ & NS \\
\hline CA3 & $5.06 \pm 0.62$ & $14.52 \pm 1.20$ & $40.31 \pm 3.33$ & 0 & $*$ & $\dagger$ & $\dagger$ \\
\hline DG & $14.74 \pm 1.59$ & $20.28 \pm 1.22$ & $61.09 \pm 5.32$ & 0 & NS & $\dagger$ & $\dagger$ \\
\hline $\mathrm{Ce}$ & $15.44 \pm 2.02$ & $43.38 \pm 2.23$ & $15.44 \pm 1.08$ & 0 & $\dagger$ & NS & $\dagger$ \\
\hline $\mathrm{BL}$ & $16.66 \pm 1.14$ & $33.44 \pm 1.99$ & $18.09 \pm 2.13$ & 0 & $\dagger$ & NS & $\dagger$ \\
\hline Tc & $28.00 \pm 2.14$ & $49.59 \pm 4.79$ & $99.75 \pm 13.52$ & 0 & NS & $\dagger$ & $*$ \\
\hline
\end{tabular}

Vehicle, $0.1 \mathrm{M}$ tartaric acid; HAL, haloperidol; mPFC, medial prefrontal cortex; NAC-C, nucleus accumbens core NAC-S, nucleus accumbens shell DG, dentate gyrus; Ce, central amygdala; BL, basolateral amygdala; Tc, temporal cortex; NS, non-significant. ${ }^{*} p<0.05$; ${ }^{\dagger} p<0.001$.

These results are in contrast with previous reports ${ }^{6,9)}$ that haloperidol induced comparable c-Fos expression in both the core and the shell of the NAC, whereas atypical antipsychotics such as clozapine, sulpiride, and aripiprazole produced greater c-Fos expression in the NAC-S than in the NAC-C. Evidence suggests that dopaminergic innervation of the NAC-C is associated with the nigrostriatal system while that of the NAC-S is associated with the mesolimbic system. ${ }^{10)}$ Therefore, it has been suggested that the preferential effect of atypical antipsychotics on the NAC-S over the NAC-C may explain the lower propensity of atypical antipsychotics to cause extrapyramidal motor side effects. As aripiprazole causes few extrapyramidal motor side effects, we expected a preferential effect of aripiprazole on the NAC-S, which was not the case. The explanation for this is not clear at the present. One difference is that Semba et al. ${ }^{11)}$ measured c-fos mRNA expression instead of the protein product, Fos, that was measured in our study. To investigate the mechanism by which aripiprazole results in few extrapyramidal motor side effects further, measurement of c-fos expression in the dorsolateral striatum should be included in future studies.

We obtained different results in the $\mathrm{MPFC}$ with aripiprazole and haloperidol treatments. Aripiprazole treatment induced a significant increase in FLI in the mPFC, but haloperidol treatment did not. Our finding that there was no effect of haloperidol on FLI in the mPFC is in agreement with previous studies. ${ }^{1,12)}$ To the best of our knowledge, this is the first report to demonstrate a significant increase in FLI in the $\mathrm{mPFC}$ resulting from aripiprazole. Other findings regarding the action of aripiprazole in the PFC come from microdialysis studies, ${ }^{13,14}$ in which a low dose of $0.3 \mathrm{mg} / \mathrm{kg}$ aripiprazole produced a significant increase in dialysate dopamine levels in the mPFC. Together, these findings lend supporting evidence to the idea that atypical antipsychotics alleviate the negative symptoms of schizophrenia by activation of the mPFC. However, it should be noted that the results of some previous studies oppose this idea. In one study, continuous arterial spin-labeling magnetic resonance imaging did not measure a change in blood perfusion to the mPFC in response to aripiprazole treatment, ${ }^{8)}$ and in another study extracellular dopamine levels in mPFC dialysates did not change significantly after aripiprazole treatment. $^{11,15)}$

The major finding of the present study is that both aripiprazole and haloperidol significantly increased FLI in the HIP, Tc, and Amyg. In the HIP and Tc, high doses of aripiprazole $(30 \mathrm{mg} / \mathrm{kg})$ and haloperidol $(1 \mathrm{mg} / \mathrm{kg})$ produced the greatest increase in FLI. There have been conflicting results with regard to the effects of antipsychotics in the Tc: single injections of haloperidol and metoclopramide did not alter Fos expression in the inferior Tc; ${ }^{16)}$ a 14-day treatment with clozapine or haloperidol produced increased or decreased levels of $\mathrm{D}_{2}$ mRNA, respectively; ${ }^{17)}$ and, a 6-month treatment with various antipsychotics increased the level of mRNA encoding the D2 dopamine receptor in the Tc. ${ }^{18)}$ Nevertheless, the new proposal that the $\mathrm{Tc}$ is a common site of action for antipsychotics is of great interest. Many neuroimaging studies suggest that the Tc is a key area associated with the pathogenesis of auditory hallucination, and $25-30 \%$ of schizophrenic patients show persistent auditory hallucination despite appropriate pharmacotherapy. ${ }^{19)}$ It is interesting to note that the superior efficacy of clozapine may be explained by its preferential action in the cerebral cortex over the striatum. ${ }^{18)}$ Regional selectivity, although debatable, is certainly a key 


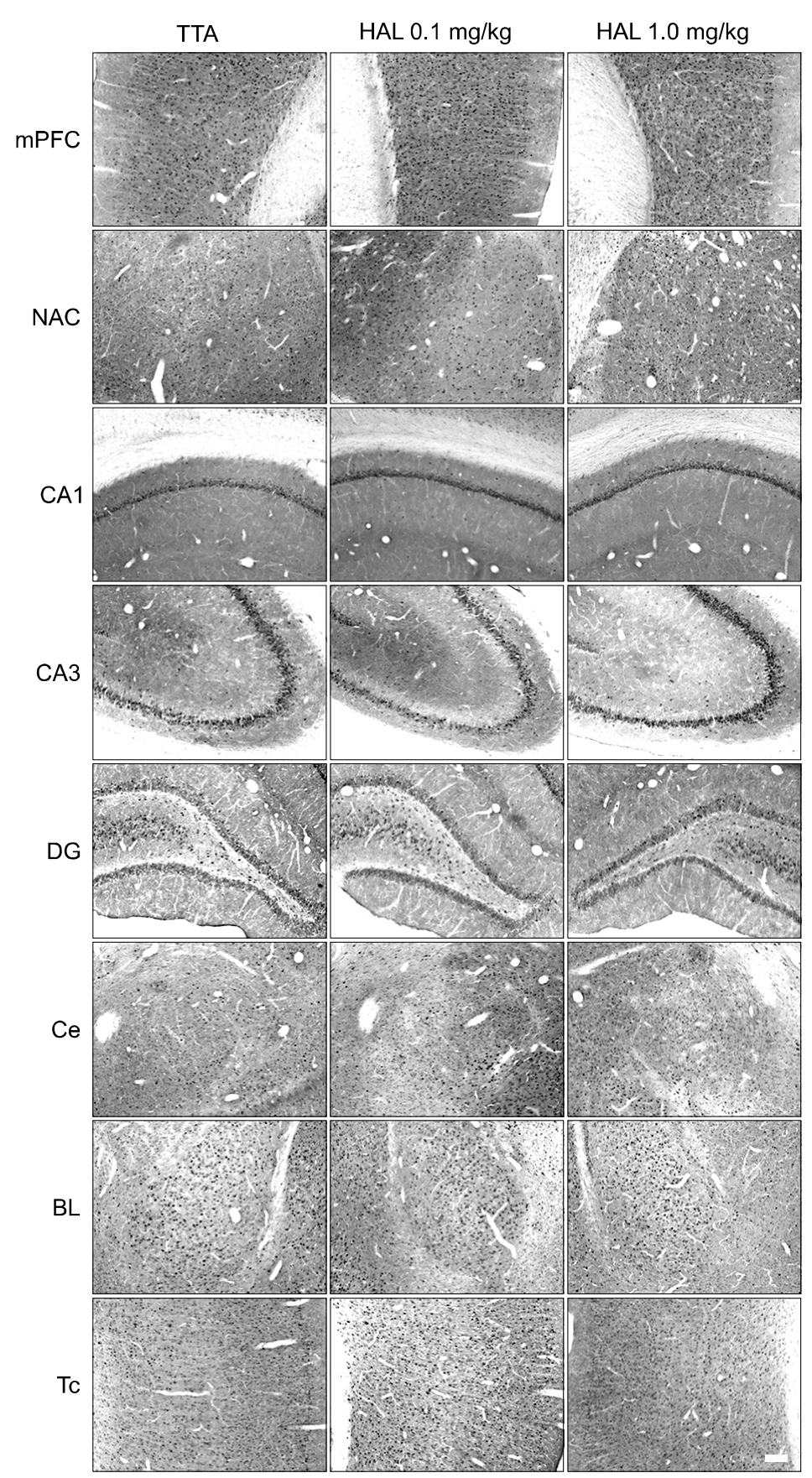

Fig. 2. Representative photomicrographs illustrating the number of Fos-positive neurons in the rat brain after single exposure to antipsychotic agents. TTA, tartaric acid; HAL, haloperidol-treated; MPFC, medial prefrontal cortex; NAC, nucleus accumbens; DG, dentate gyrus; $\mathrm{Ce}$, central amygdala; BL, basolateral amygdala; Tc, temporal cortex. $\mathrm{N}=8$ rats/group. Scale bar: 100 um. concept that may be applicable in developing new antipsychotics. The amygdala is implicated in a variety of functions, including the expression of fear and the modulation of memory. It receives dopaminergic innervations from the ventral tegmental area ${ }^{20)}$ and is closely interconnected with the PFC and NAC. ${ }^{21,22)}$ We observed a significant increase in FLI in the Ce and BL after all doses $(1.0,10$ or $30 \mathrm{mg} / \mathrm{kg})$ of aripiprazole, but a low dose of 0.1 $\mathrm{mg} / \mathrm{kg}$ of haloperidol produced a significant increase in
FLI only in the Ce and BL. These findings regarding haloperidol treatment are consistent with the findings of other studies, ${ }^{23,24)}$ implying that haloperidol has a limited effect in this area. On the other hand, clozapine $(10-20 \mathrm{mg} / \mathrm{kg})^{23)}$ and olanzapine $(10 \mathrm{mg} / \mathrm{kg})^{24)}$ both produce a significant increase in FLI in the Amyg. Therefore, these findings suggest that the induction of FLI in the Amyg, as in the PFC, might be a way to differentiate atypical from typical antipsychotics. 
Several methodological considerations should be mentioned. In a preliminary experiment, we compared c-FOS expression between rats exposed to a habituation handling procedure for 3-4 days with naïve rats. The results showed significantly less induction of c-FOS expression in the rats exposed to handling. Hence, a habituation handling procedure for 4 days before the experiment was adopted as a standard procedure in the present study, which might be one of the strengths of our study. Another difference between our study and others is the time point for sacrificing animals after drug injection, which was $2 \mathrm{~h}$ in our study. We chose $2 \mathrm{~h}$ based on the fact that the protein product, Fos, peaks between 2 and $6 \mathrm{~h}$ after an acute challenge. ${ }^{25)}$ However, there are many studies in which animals were sacrificed $4 \mathrm{~h}$ after acute drug administration. This difference may explain why we did not find that aripiprazole treatment preferentially affected FLI in the NAC-S over the NAC-C. The time point for sacrificing animals, therefore, should be considered in future studies.

In conclusion, these findings suggest that acute administration of aripiprazole or haloperidol significantly increases FLI in various brain areas, including the mPFC, NAC-S, NAC-C, CA1, CA3, DG, Ce, BL, and Tc. The differential action of aripiprazole but not haloperidol treatment on FLI in the mPFC and Amyg may be a good way to differentiate atypical from typical antipsychotics.

\section{Acknowledgments}

Funding for this study was provided by the Otsuka Pharmaceutical Company, Korea in the form of an unrestricted grant.

\section{REFERENCES}

1. Robertson GS, Matsumura H, Fibiger HC. Induction patterns of Fos-like immunoreactivity in the forebrain as predictors of atypical antipsychotic activity. J Pharmacol Exp Ther 1994;271:1058-1066.

2. Lidow MS, Williams GV, Goldman-Rakic PS. The cerebral cortex: a case for a common site of action of antipsychotics. Trends Pharmacol Sci 1998;19:136-140.

3. Pilowsky LS, Mulligan RS, Acton PD, Ell PJ, Costa DC, Kerwin RW. Limbic selectivity of clozapine. Lancet 1997; 350:490-491.

4. Benes FM. Evidence for altered trisynaptic circuitry in schizophrenic hippocampus. Biol Psychiatry 1999;46:589599.

5. Chung YC, Park IS, Li Z, Dai J, Meltzer HY, Ichikawa J. Clozapine, but not haloperidol, increases hippocampal dopamine and acetylcholine release. Clinical Psychopharmacology and Neuroscience 2003;1:79-85.

6. Natesan S, Reckless GE, Nobrega JN, Fletcher PJ, Kapur S. Dissociation between in vivo occupancy and functional antagonism of dopamine D2 receptors: comparing aripipra- zole to other antipsychotics in animal models. Neuropsychopharmacology 2006;31:1854-1863.

7. Ozdemir V, Fourie J, Ozdener F. Aripiprazole (Otsuka Pharmaceutical Co). Curr Opin Investig Drugs 2002;3:113-120.

8. Nordquist RE, Risterucci C, Moreau JL, von Kienlin M, Künnecke B, Maco M, et al. Effects of aripiprazole/OPC14597 on motor activity, pharmacological models of psychosis, and brain activity in rats. Neuropharmacology 2008;54: $405-416$

9. Semba J, Sakai MW, Suhara T, Akanuma N. Differential effects of acute and chronic treatment with typical and atypical neuroleptics on c-fos $m R N A$ expression in rat forebrain regions using non-radioactive in situ hybridization. Neurochem Int 1999;34:269-277.

10. Deutch AY, Lee MC, Iadarola MJ. Regionally specific effects of atypical antipsychotic drugs on striatal Fos expression: the nucleus accumbens shell as a locus of antipsychotic action. Mol Cell Neurosci 1992;3:332-341.

11. Semba J, Watanabe A, Kito S, Toru M. Behavioural and neurochemical effects of OPC-14597, a novel antipsychotic drug, on dopaminergic mechanisms in rat brain. Neuropharmacology 1995;34:785-791.

12. Wan W, Ennulat DJ, Cohen BM. Acute administration of typical and atypical antipsychotic drugs induces distinctive patterns of Fos expression in the rat forebrain. Brain Res 1995;688:95-104.

13. Li Z, Ichikawa J, Dai J, Meltzer HY. Aripiprazole, a novel antipsychotic drug, preferentially increases dopamine release in the prefrontal cortex and hippocampus in rat brain. Eur J Pharmacol 2004;493:75-83.

14. Zocchi A, Fabbri D, Heidbreder CA. Aripiprazole increases dopamine but not noradrenaline and serotonin levels in the mouse prefrontal cortex. Neurosci Lett 2005;387:157-161.

15. Assié MB, Ravailhe V, Faucillon V, Newman-Tancredi A. Contrasting contribution of 5-hydroxytryptamine $1 A$ receptor activation to neurochemical profile of novel antipsychotics: frontocortical dopamine and hippocampal serotonin release in rat brain. J Pharmacol Exp Ther 2005;315:265-272.

16. Deutch AY, Lewis DA, Whitehead RE, Elsworth JD, Iadarola MJ, Redmond DE Jr, et al. Effects of D2 dopamine receptor antagonists on Fos protein expression in the striatal complex and entorhinal cortex of the nonhuman primate. Synapse 1996;23:182-191.

17. Damask SP, Bovenkerk KA, de la Pena G, Hoversten KM, Peters DB, Valentine AM, et al. Differential effects of clozapine and haloperidol on dopamine receptor $m R N A$ expression in rat striatum and cortex. Brain Res Mol Brain Res 1996;41:241-249.

18. Lidow MS, Goldman-Rakic PS. Differential regulation of D2 and D4 dopamine receptor mRNAs in the primate cerebral cortex vs. neostriatum: effects of chronic treatment with typical and atypical antipsychotic drugs. J Pharmacol Exp Ther 1997;283:939-946.

19. Carter DM, Mackinnon A, Copolov DL. Patients'strategies for coping with auditory hallucinations. J Nerv Ment Dis 1996;184:159-164.

20. Beckstead RM, Domesick VB, Nauta WJ. Efferent connections of the substantia nigra and ventral tegmental area in the rat. Brain Res 1979;175:191-217.

21. De Olmos JS, Alheid GF, Beltramino CA. Amygdala. In: Paxinos $G(E d)$, The Rat Nervous System. 1st ed. Sydney: Academic Press;1985. p. 223-334.

22. Heimer L, Alheid GF, de Olmos JS, Groenewegen HJ, Haber SN, Harlan RE, et al. The accumbens: beyond the core-shell dichotomy. J Neuropsychiatry Clin Neurosci 
1997;9:354-381.

23. Pinna A, Morelli M. Differential induction of Fos-like-immunoreactivity in the extended amygdala after haloperidol and clozapine. Neuropsychopharmacology 1999;21:93-100.

24. Seillier A, Coutureau E, Thiriet N, Herbeaux K, Zwiller J, Di Scala G, et al. Bilateral lesions of the entorhinal cortex differentially modify haloperidol- and olanzapine-induced c-fos mRNA expression in the rat forebrain. Neuropharmacology 2003;45:190-200.

25. Kaczmarek L, Robertson HA. Immediate early genes and inducible transcription factors in mapping of the central nervous system function and dysfunction. In: Bjorklund A, Hokfelt T, editors. Handb Chem Neuroanat. Vol. 19. Elsevier; Amsterdam; 2002. 